\title{
Emotional Abuse: Agony for Adolescents
}

\author{
Falak Nesheen ${ }^{1}$, Dr. Shah Alam ${ }^{2}$
}

\section{ABSTRACT:}

Adolescence is a period of transition during which an individual experiences not only profound physical, physiological, cognitive and emotional changes but also experience many emotional abuse. The transition from childhood to adolescence may be challenging time for majority of young people. Emotional Abuse as recently stated in a maltreatment prevention guide proves to be detrimental for child's physical, social, mental and spiritual development. Emotional abuse has been variously characterized as "the use of verbal and non-verbal acts which symbolically hurt the other or the use of threats to hurt the other". The basic aim of this paper is to explore the kinds of emotional abuse and then suggest various strategies to overcome such aspects of life. The paper reports a series of factors responsible for the torment among the emotionally abused adolescents or the excruciation they go through. This paper also highlights the role played by parents, teachers and peers in emotional abuse such as shame and humiliation, rejection and ignoring, terrorizing, isolating and corrupting etc. Studies during the last decades have consistently documented impaired cognitive abilities and poor academic achievement along with aggression, irritability, hyper vigilance, suicidal tendencies, paranoia and substance uses behavior among emotionally abused adolescents. If Emotional abuse remains a routine task in the life of an adolescent, it may have long term consequences at every walk of his/her life.

Keywords: Emotional abuse, Agony, and adolescents.

Emotional abuse is the most challenging and prevalent form of abuse .As recently stated in a mal treatment prevention guide (WHO,2006) that acts of emotional abuse are considered to have high likelihood of adversely affecting child's mental health and also his spiritual, moral and social de velopment. It has been proved by various studies that emotional abuse impaired cognitive abilitie $\mathrm{s}$ and poor academic achievement along with aggression, irritability, hypervigilence and suicidal tendencies and substance use behavior among emotionally abused adolescents.

The common problem among adolescents of modern era is to become frustrated and depressed ea sily. Either by getting poor grades, being scolded by parents or teachers, problems in their peer ci rcles and also the environmental situations. As a result of which they find themselves at the edge of being susceptible to certain tendencies including the most gruesome and widely used suicidal $t$ endency. They become too much depressed and frustrated that they put their lives in danger.

\footnotetext{
${ }^{1}$ Research Scholar, Department of Psychology A.M.U Aligarh

${ }^{2}$ Associate professor, Department of Psychology A.M.U Aligarh

(C) 2015 I F Nesheen, S Alam; licensee IJIP. This is an Open Access Research distributed under the terms of the Creative Commons Attribution License (http://creativecommons.org/licenses/by/2.0), which permits unrestricted use, distribution, and reproduction in any Medium, provided the original work is properly cited.
} 
When adolescents are abused, it can affect every aspect of their lives, especially self-esteem. Ho w much harm is done often depends on the situation and sometimes on how severe the abuse is. Every family has arguments. Friends, couples, coaches, and teachers can get upset, frustrated, or have a bad day. We all go through difficult times when someone is stressed and angry. Punishme nts and discipline - like removing privileges, grounding, or being sent to your room - are com mon. Yelling and anger can happen in lots of parent-teen relationships and in friendships - altho ugh it can feel pretty bad to have an argument with a parent or friend. But if punishments, argum ents, or yelling go too far or last too long it can lead to stress and other serious problems. Teens who are abused (or have been in the past) often have trouble sleeping, eating, and concentrating. They may not do well at school because they are angry or frightened, or feel like they just don't c are anymore.

Many people who are abused distrust others. They may feel a lot of anger toward other people an $\mathrm{d}$ themselves, and it can be hard to make friends. Abuse is a significant cause of depression in yo ung people. Some teens can only feel better by doing things that could hurt them like cutting or a busing drugs or alcohol. They might even attempt suicide. It's common for those who have been abused to feel upset, angry, and confused about what happened to them. They may feel guilty an $\mathrm{d}$ embarrassed and blame themselves. But abuse is never the fault of the person who is being abu sed, no matter how much the abuser tries to blame others.

\section{Introduction}

Emotional abuse of children and adolescents may be the most challenging and prevalent form of child abuse and neglect, but until recently, it has received relatively little attention. The America $\mathrm{n}$ Academy of Pediatrics (AAP) reviewed the topic in a technical report in 2002. 1 This clinical $\mathrm{r}$ eport updates the pediatrician on current knowledge and approaches to psychological maltreatme nt, with guidance on its identification and effective methods of prevention and treatments/interve ntion.

\section{Definition}

There is no universally agreed definition of psychological maltreatment or emotional maltreatme nt, terms that are often used interchangeably. Psychological maltreatment encompasses both the cognitive and affective components of maltreatment. One of the difficulties in clearly defining $\mathrm{w}$ hat such maltreatment comprises involves the absence of a strong societal consensus on the distin ction between psychological maltreatment and suboptimal parenting. Exposure to psychological maltreatment is considered when acts of omission or commission inflict harm on the child's well -being, which may then be manifested as emotional distress or maladaptive behavior in the child. Psychological maltreatment is difficult to identify, in part because such maltreatment involves “ a relationship between the parent and the child rather than an event or a series of repeated events occurring within the parent-child relationship."

Emotional abuse refers to a repeated pattern of parental behavior that is likely to be interpreted $b$ $\mathrm{y}$ a child that he or she is unloved, unwanted, or serves only instrumental purposes and/or that se 
verely undermines the child's development and socialization. Recent conceptualization of psych ological maltreatment focuses on the caregivers behaviors as opposed to the disturbed behaviors in the child. Such behaviors of the caregiver include acts of omission (ignoring the need for socia 1 interaction) or commission (spurning, terrorizing); may be verbal or nonverbal, active or passiv e, and with or without intent to harm; and negatively affect the child's cognitive, social, emotion al, and/or physical development.

\section{Patterns of emotional abuse}

Emotional abuse falls into three patterns:

1. Aggressive: which includes name-calling, belittling, blaming, accusing, yelling ,screaming, making threats, degrading insults or destructive criticism.

2. Denying: this includes sulking, manipulation, neglecting, not listening, withholding affectio $\mathrm{n}$ and distorting the other's experience.

3. Minimizing: this can include belittling the effect of something, isolating, accusations of exa ggerating or inventing and offering solutions or 'advice'.

\section{Signs of emotional abuse;}

a. Depression or anxiety

b. Increased isolation from friends and family

c. Fearful or agitated behavior

d. Lower self-esteem and self-confidence

e. Addiction to alcohol or drugs

f. Escapist behavior

Emotional abuse can damage a person's confidence so that they feel worthless and find it hard to make or keep other relationships. Secrecy and shame usually maintain the abuse.

Emotional abuse of a child is commonly defined as a pattern of behavior by parents or caregivers that can seriously interfere with a child's cognitive, emotional, psychological or social developm ent. Emotional abuse of a child - also referred to as psychological maltreatment — can include:

- Ignoring. Either physically or psychologically, the parent or caregiver is not present to respo nd to the child. He or she may not look at the child and may not call the child by name.

- Rejecting. This is an active refusal to respond to a child's needs (e.g., refusing to touch a chil $\mathrm{d}$, denying the needs of a child, ridiculing a child).

- Isolating. The parent or caregiver consistently prevents the child from having normal social i nteractions with peers, family members and adults. This also may include confining the child or limiting the child's freedom of movement.

- Exploiting or corrupting . In this kind of abuse, a child is taught, encouraged or forced to dev elop inappropriate or illegal behaviors. It may involve self-destructive or antisocial acts of th e parent or caregiver, such as teaching a child how to steal or forcing a child into prostitution

- Verbally assaulting. This involves constantly belittling, shaming, ridiculing or verbally threat ening the child.

- Terrorizing. Here, the parent or caregiver threatens or bullies the child and creates a climate of fear for the child. Terrorizing can include placing the child or the child's loved one (such 
as a sibling, pet or toy) in a dangerous or chaotic situation, or placing rigid or unrealistic exp ectations on the child with threats of harm if they are not met.

- Neglecting the child. This abuse may include educational neglect, where a parent or caregive $r$ fails or refuses to provide the child with necessary educational services; mental health negl ect, where the parent or caregiver denies or ignores a child's need for treatment for psycholo gical problems; or medical neglect, where a parent or caregiver denies or ignores child's nee $\mathrm{d}$ for treatment for medical problems

\section{CAUSES:}

There is a dearth of knowledge surrounding the causes of emotional abuse. Much of the literature devoted to the investigation or delineation of aspects of emotional abuse discusses the etiology $i$ $\mathrm{n}$ terms of child maltreatment in general (e.g. Wolfe 1991); that is, the effect of parental and chil $\mathrm{d}$ characteristics and socio-cultural context on the propensity for abuse. However, adults or paren ts who emotionally abuse are frequently described as poorly equipped with the knowledge to cop e effectively with children's normal demands at different developmental stages (Oates 1996). A s tudy comparing emotionally abusive parents with a closely matched control group of 'problem' $\mathrm{p}$ arents in a day nursery (Brazelton 1982, as cited in Oates 1996), indicated that emotionally abusi ve parents showed poorer coping skills, poorer child management strategies, and more difficulty in forming and maintaining relationships. These parents also reported more deviant behavior in $\mathrm{t}$ heir children displayed than parents in the control group. Previous Clearing House publications $h$ ave described a number of parental and child characteristics that may enhance the potential for e motional abuse.

For example, two of the most prevalent mental disorders identified as affecting parents who malt reat their children, namely depression and substance abuse (Chaffin, Kelleher \& Hollenberg 199 6), are likely to increase the potential for emotionally abusive responses (see Child Maltreatment and Mental Disorder (Tomison 1996b) and Child Maltreatment and Substance Abuse (Tomison 1996c) for a more detailed discussion). Similarly, neuropsychological deficits or intellectual disa bility may increase the likelihood for inappropriate parenting and/or emotional abuse as a functio $\mathrm{n}$ of the added stress such conditions may produce (Tomison 1996a). With regard to child charact eristics, a child with a physical or intellectual disability may be more vulnerable to emotional abu se because of the greater potential for disruptions in mother-child bonding and/or greater parental stress (see Child Maltreatment and Disability (Tomison1996a).

Causes of emotional abuse Powerlessness, hurt, fear and anger are often unresolved issues for bo th the abuser and the abused. Childhood patterns can be re-enacted in emotional abuse with one $p$ articipant taking the 'parent' role and the other adopting that of the 'child'. A person may also be an abuser in one relationship and abused in another as they reverse unresolved emotions. Abuser $\mathrm{s}$ find it difficult to handle their feelings and blame their problems on others instead.

\section{CONSEQUENCES OF EMOTIONAL ABUSE:}

Experiencing child abuse has been linked to a variety of negative consequences, including post-tr aumatic stress, depression, suicide, substance abuse, and obesity (Hornor, 2010).

The long-term impact of emotional maltreatment has not been studied widely, but recent studies 
have begun to document its long-term consequences. Emotional maltreatment has been linked wi th increased depression, anxiety, somatic complaints, and difficulties in interpersonal relationshi ps (Spertus, Wong, Halligan, \& Seremetis, 2003)

Anger and aggression are potentially destructive forms of psychological problems in adulthood. Allen (2010) examined the impact of long-term child emotional abuse on aggression using the sa me sample previously described. Allen specifically tested the self-capacities of interpersonal rela tedness, identity, and affect regulation as mediators for the impact of emotional abuse on aggress ion in adulthood. Results suggested that emotional abuse is significantly predictive of participant s' self-reported increased levels of various forms of aggression.

Detrimental alterations of self-capacities were found to predict aggression. It is possible that exp eriencing emotional maltreatment teaches the child ineffective ways of relating to others; the chil $d$ then develops poor relationship skills that increase the likelihood of interpersonal problems as an adult. Problematic relationships result in an increased likelihood of verbal and/or physical agg ression. Also, experiencing emotional abuse may result in an inability to develop adequate emoti onal regulation skills, which increases the risk of persons being unable to rid themselves of negat ive feelings of anger, predisposing them to overt forms of aggression.

Emotional abuse also was significantly correlated with all of the self-capacities (identity, interper sonal relatedness, and affect regulation) and was found to be significant independent predictor of interpersonal problems and affect regulation.Detrimenta alterations of self-capacities were found to predict aggression.

The effects of emotional maltreatment can be disabling and enduring and should be carefully ass essed. Shaffer, Yates, and Egeland (2009) examined if and how different forms of emotional mal treatment contributed to adolescent adjustment via aggression and social withdrawal in middle ch ildhood.

\section{PREVALENCE:}

\section{In intimate relationships;}

Domestic abuse - defined as chronic mistreatment in marriage, families, dating and other intimat e relationships - can include emotionally abusive behavior.

\section{In the family;}

Emotional abuse of a child is commonly defined as a pattern of behavior by parents or caregivers that can seriously interfere with a child's cognitive, emotional, psychological or social developm ent. Some parents may emotionally and psychologically harm their children because of stress, po or parenting skills, social isolation, and lack of available resources or inappropriate expectations of their children. They may emotionally abuse their children because the parents or caregivers $\mathrm{w}$ ere emotionally abused during their childhood.

\section{In Schools}

A particular form of systems abuse that is not frequently mentioned in the literature, is emotional abuse within educational settings. A number of studies have indicated that a proportion of teache rs commonly use emotional abuse in conjunction with other punitive disciplining practices as a means of exerting control (Hart, Germain \& Brassard 1987 ;) 


\section{Media Reporting}

Finally, although not strictly a form of systems abuse, the extent of media reporting on child abus e and children may, in itself, constitute emotionally or psychologically abusive activity at the soc ietal level (Franklin \& Horwath 1996).

\section{Systems Abuse}

Systems abuse may be defined as the 'harm done to children in the context of policies or program $\mathrm{s}$ designed to provide care or protection. Children's welfare, development or security is undermin ed by the actions of individuals or by the lack of suitable policies, practices and procedures withi n systems or institutions' (Cashmore, Dolby \& Brennan 1994, p.10). This broad definition encom passes acts of commission and omission (neglect), and allows for the promotion of aspects of chi ld development that are likely to produce optimal outcomes for children, rather than merely focu sing on harm minimization (Cashmore, Dolby \& Brennan 1994). Typically, systems abuse can b e characterized as involving one or more of the following: the failure to consider children's needs ; the unavailability of appropriate services for children; a failure to effectively organize and coor dinate existing services; and institutional abuse (i.e. child maltreatment perpetrated within agenci es or institutions with the responsibility for the care of children (Cashmore, Dolby \& Brennan 19 94).

\section{Prevention:}

Although there is evidence that emotional abuse has longstanding and serious impacts on childre n's development and social functioning, public intervention in these cases is limited (Daro1988). Despite a number of practice models proposed for working with sexually and physically abused c hildren and their families (Giarretto 1978; Dale et al.1986), little attention has been paid to how b est to help adolescents recover from the traumatic effects of emotional abuse. Few preventive me asures include;

\section{Family Support:}

Many of the strategies suggested to prevent emotional abuse are adaptations of more generalist fa mily support programs. Fortin and Chamberland (1995) suggest a combination of alleviating soci o-environmental stress, a reduction in familial dysfunction, the promotion of parenting skills and a positive self- concept, and social support.

\section{Community Education:}

Despite the growing acknowledgment of child maltreatment as a societal problem, it is often diffi cult to convince those in the broader community that they, themselves, may be part of the proble $\mathrm{m}$. It is easier to think of maltreaters in stereotypical ways, pathologising them as mentally ill, ab normal or evil, enabling non-offenders to distance themselves from the problem rather than to ad dress the true causes of maltreatment, such as poverty, or a lack of social support (Wilczynski \& Sinclair 1996).

\section{Child and Family Center's - The 'One Stop Shop':}

The values underlying Powell's Child and Neighborhood Program approach (1987, as cited in Vi nson, Baldry and Hargreaves 1996) are incorporated into a relatively new development that has b 
egun operating in Australia. Child and Family Centres, frequently referred to as 'one stop shops', are multiservice community centers which aim to provide a local, non-stigmatising family suppo rt service that encourages families to proactively seek assistance.

\section{Support Networks for Parents and Caregivers:}

Conversely, one factor which increases the propensity for emotional maltreatment is social isolat ion (Garbarino \& Garbarino 1994). Parents need access to multiple perspectives on their child, th emselves and on parent-child relationships. Each perspective provides 'separate, distinct, and spe cial information to the parent [and to the child]' (Garbarino \& Garbarino 1994, p.21), without wh ich any parental disturbance or child behavioural problem may escalate into a pattern of emotion al abuse. Although not focused specifically on emotional abuse, Vinson, Baldry and Hargreaves ( 1996) conducted a study with important findings for the prevention of all maltreatment, assessing two adjoining neighbourhoods in Western Sydney which were both economically depressed but had contrasting rates of child maltreatment. Their intention was to determine why the difference $i$ $\mathrm{n}$ the rate of child maltreatment existed and whether this could be attributed to differences in the characteristics of the neighbourhoods as social entities.

\section{CONCLUSION}

We may conclude that if the adolescents were nurtured and supported, they will overcome the negative effects or signs of emotional abuse. Different measures can be taken in order to handle the abusive situations. The focus should be on dysfunctional and broken families, so that parents should be guided properly and were assisted to maintain good relation with their children's and also keep good line of communication with them. These things may reduce the occurrence of abusive environment. Working with the counselor is one way to sort through the complicated feelings and reactions that being abused creates, and the process can help to rebuild feelings of safety, confidence and self esteem. Finally it is a valuable skill for adolescent to adapt well in the face of hard times.

\section{REFERENCES}

Iwaniec D, (1997). An overview of emotional maltreatment and failure to thrive. Child abuse Re v. 370-388.

Loh CC,Vostains P, (2004). Perceived mother-infant relationship difficulties in postnatal depres sion. Infant Child Dev.

Doyle C, (2002). Emotional abuse of children: issues for intervention.

Gilbert R., Wisdom CS., Browne K., Fergusson D., Webb E., Janson S, ( 2009). Burden and con sequences of child maltreatment in high income countries.

Glaser D, (2002). Emotional abuse and neglect( Psychological maltreatment): A conceptual fra me work.

Thompson AE, Kaplin CA, (1996). Childhood emotional abuse. British journal of psychiatry

Smith, Melinda, Segal, Jeanne,(2013). "Domestic violence and abuse: signs of abuse and abusiv e relationships". 